\title{
Genetic Variability and Character Association in Upland Rice (Oryza sativa L.) Genotypes, Southwestern Ethiopia
}

\author{
Altaye Tiruneh \\ Altaye Tiruneh, Southern Agricultural Research Institute, Bonga Agricultural Research Center, \\ P.O.BOX 101, Bonga, Ethiopia
}

\begin{abstract}
This study aimed to estimate the genetic variability of 36 upland rice genotypes for yield and its components, and determine trait association among morphological traits. The field experiment was conducted using simple lattice design at two locations (Guraferda and Gojeb) during 2016 main cropping season. Analysis of variance for individual locations revealed significant differences $(\mathrm{P} \leq 0.05)$ among genotypes for most of the studied traits at Guraferda, however number of fertile tillers per plant, number of unfilled grains per panicle, non-fertile tillers per plant, panicle length, thousand grain weight and biological yield were found being non-significant. Similarly, the genotypes showed significant difference $(\mathrm{P} \leq 0.05)$ for plant height, number of filled grain per panicle, days to maturity, number of primary branches per panicle and grain yield however the remaining traits were showed nonsignificant difference among genotypes at Gojeb. Combined analysis of variance over the two locations revealed significant differences $(\mathrm{P} \leq 0.05)$ among the genotypes for most of the studied traits, while genotype $\mathrm{x}$ location interactions showed significant differences for the traits, total number of tillers per plant, plant height, days to $50 \%$ heading, days to maturity and grain yield. The mean over the two locations showed, wide ranges for number of filled grains per panicle (24-123), days to 50\% heading (50-83) and grain yield (15-34 q/ha). The genotypic coefficient of variation ranged from $2.3 \%$ for plant height to $19.5 \%$ for number of filled grains per panicle, and phenotypic coefficient of variation (PCV) ranged from $4.0 \%$ for panicle length to $20.2 \%$ for filled grains per panicle. High broad sense heritability $\left(\mathrm{H}^{2} \mathrm{~B}\right)$ estimates were obtained for number of filled grains per panicle $(93.3 \%)$ and days to $50 \%$ heading $(61.6 \%)$; while low $\mathrm{H}^{2} \mathrm{~B}$ value was found for plant height $(20.1 \%)$, number of primary branches per panicle (15.1\%) and grain yield (14.4\%). The estimates of genetic advance as the percentage of the mean (GAM) ranged from $2.1 \%$ for plant height to $38.8 \%$ for number of filled grains per panicle. High $\mathrm{H}^{2} \mathrm{~B}$ coupled with high GAM were obtained for number of filled grains per panicle, which indicates that this trait can be effectively improved through selection. Grain yield showed significant and positive genotypic correlation with 1000 -grain weight, days to $50 \%$ heading, days to maturity and harvest index. Similarly, it showed significant and positive phenotypic correlation with panicle length, number of filled grains per panicle, 1000-grain weight, fertile tillers per plant and number of primary branches per panicle. Path coefficient analysis at genotypic level revealed high and positive direct effect of days to heading $(0.7), 1000$-grain weight $(0.6)$, days to maturity $(0.3)$ and harvest index (0.2). The detected positive correlation indicated that, increases in the value of one trait results in increasing the correlated traits.
\end{abstract}

Keywords: Broad sense heritability, Upland rice, Variability,

DOI: $10.7176 / \mathrm{JBAH} / 9-3-02$

\section{INTRODUCTION}

Rice is one of the most important cereal crops globally with an annual production of 483.3 million metric tons on milled basis, in 2016 (USDA, 2016). Of the 25 major rice producing nations, 17 are in South, Southeast, or East Asia. In 2015/2016, China, India, and Indonesia are the top three rice-producing countries with $28.4 \%, 21.2 \%$ and $9.6 \%$ percentage of the world's total production (FAO, 2016). In Africa, rice production has reached 26.2 million tons and about 20 million people of the continent depends on rice production for their direct consumption, thereby, more than 40 countries of the continent cultivate and consume rice (Alemu and Assefa, 2016; FAO, 2016). According to the report of Jeon et al. (2011), the amount of rice consumption in the world is increasing at the rate of more than $1.5 \%$; while its production increases at the rate of $1 \%$. The demand of rice in Africa is growing swiftly with an annual growth rate of $6 \%$ per year (Hadush, 2015). In Africa, rice consumption is replacing maize, teff and cassava, but African production has not met this shift of crop, and hence, Africa imports large quantity of rice (Dugan, 2015).

It is believed that, rice was introduced to Ethiopia in the 1970s, and has since been cultivated in relatively few parts of the country (Heluf and Mulugeta, 2006). In the nations, rice production is estimated to be $131,821.8$ $\mathrm{t}$ per annum harvested from $46,832.2$ ha of land, and with an average productivity of $2.8 \mathrm{t} \mathrm{ha}^{-1}$ (CSA, 2016). The three-main rice producing regions of the country: namely, Amhara, Oromia and SNNPR have $76 \%, 14.9 \%$, and $5.2 \%$ of the country's rice production, respectively (EIAR, 2013). In terms of areas of production, it shows a growing importance in the country, which is reflected in the increase in the area of production from 24,434 ha in the year 2000 to 46,832 ha in 2016, which is almost doubled during this period (CSA, 2000; CSA, 2016). The average rice productivity in Ethiopia is estimated at $2.8 \mathrm{t} \mathrm{ha}^{-1}$ (CSA, 2016), which is much lower than the world's 
average of $4.4 \mathrm{tha}^{-1}(\mathrm{FAO}, 2016)$.

The limited production of rice, which is mainly attributed to lack of improved varieties with better productivity and adaptability can be improved through developing high yielding varieties, which largely depends on understanding the status of divergence and convergence of the genetic variability existed in rice genotypes (Basavaraja et al.,2013; Osekita et al., 2014). This is because, plant genetic improvement in breeding programs, mainly depends on the amount of genetic variability present in the population (Dutta et al., 2013). Similarly, the direction and expected response to selection in crop improvement can be determined by estimating heritability and genetic advance, and understanding such genetic components is a useful tool for breeders, in designing appropriate breeding program (Bagati et al., 2016). Knowing the association between complex characters through correlation study helps to identify the most important characters to be considered in selection, as yield is a function of several traits (Moosavi et al., 2016). However, there is limited information on the genetic variability and character association among yield and yield related traits of these genotypes in the study areas. In fact, such study has paramount significant in understanding the extent of genetic variability and inheritance of desirable traits for the genetic improvement of the crop. Hence, the present study was undertaken with the following objectives:

$>$ To estimate the extent of genetic variability, heritability and genetic advance of upland rice genotypes.

$>$ To determine the pattern and extent of association among agronomic characters and with grain yield.

\section{MATERIALS AND METHODS}

Description of the study areas:

The field experiment was carried out during the main cropping season of 2016 in two locations ( Gojeb and Guraferda), located $439 \mathrm{Km}$ and $590 \mathrm{Km}$ from Addis Ababa, respectively. Gojeb and Guraferda experimental sites are found in Southern Nations, Nationalities, and Peoples Regional State of Kaffa and Benchi-maji zones, respectively. The two locations represent two different agro-ecologies of the region. Gojeb experimental site is located at $07^{\circ} 15^{\prime} 0^{\prime \prime} \mathrm{N}$ latitude and $036^{\circ} 0^{\prime} 0^{\prime \prime} \mathrm{E}$ longitude at an altitude of 1235 m.a.s.l. Its average annual rainfall is $1710 \mathrm{~mm}$ with a minimum and maximum temperatures of $16.7^{\circ} \mathrm{C}$ to $24^{\circ} \mathrm{C}$. The soil type of the experimental site at Gojeb is volcanic origin, and is classified as the andosol orders with clay loam texture. Guraferda experimental site is located $06^{\circ} 50^{\prime} 368^{\prime \prime}$ North, $035^{\circ} 17^{\prime} 16^{\prime \prime}$ East with an altitude of 1138 m.a.s.l. The annual average temperature ranges from 25 to $39^{\circ} \mathrm{C}$. The area receives maximum rainfall from June to September and the amount ranges between 1200 to $1332 \mathrm{~mm}$ per annum. The soil type of Guraferda is in the Acrisol orders with sandy clay loam texture. These two sites are identified as one of the ideal environments for evaluation of rice in the region (Asfaha et al., 2015).

Experimental materials: The materials used in this experiment consists of 36 upland rice genotypes, of which six were released varieties; while the remaining 30 genotypes were recently introduced from IRRI and WARDA. All of these materials were obtained from Fogera and Bonga Agricultural Research Centers (Table 1).

Table 1: Description of experimental materials (upland rice genotypes).

\begin{tabular}{|c|c|c|c|c|c|c|c|}
\hline S.no. & Genotypes & Status & Origin & S.no & Genotypes & Status & Origin \\
\hline 1 & ARCCU16Bar-22-1-1-2-B-1 & URNVT, 2015 & IRRI & 19 & IR 78937-B-20-B-B-4 & URNVT, 2015 & IRRI \\
\hline 2 & ARCCU16Bar-9-2-10-4-B-1 & URNVT, 2015 & IRRI & 20 & WAB880SG14 & URNVT, 2015 & IRRI \\
\hline 3 & ARCCU 16Bar-13-15-18-1-B-1 & URNVT, 2015 & IRRI & 21 & ARCCU16 Bar-9-20-6-1-1-1 & URNVT, 2015 & IRRI \\
\hline 4 & ARCCU 16 Bar-15-5-1-26-B-1 & URNVT, 2015 & IRRI & 22 & IR $83750-B-B-131-1$ & URNVT, 2015 & IRRI \\
\hline 5 & ARCCU 16 Br-12-12-33-3-B-1 & URNVT, 2015 & IRRI & 23 & WAB415-B-11A1-2 & URNVT, 2015 & IRRI \\
\hline 6 & ARCCU 16 Bar-12-17-3-4-B-1 & URNVT, 2015 & IRRI & 24 & ARCCU16 Bar-4-14-2-4-B-B & URNVT, 2015 & IRRI \\
\hline 7 & ARCCU 16 Bar-9-9-24-4-B-1 & URNVT, 2015 & IRRI & 25 & ARCCU16 Bar9-13-1-2-1 & URNVT, 2015 & IRRI \\
\hline $\begin{array}{l}8 \\
9\end{array}$ & $\begin{array}{l}\text { ARCCU } 16 \text { Bar9-26-29-1-B-1 } \\
\text { SUPERICA-1 }\end{array}$ & $\begin{array}{l}\text { URNVT, } 2015 \\
\text { Released }\end{array}$ & $\begin{array}{l}\text { IRRI } \\
\text { WARDA }\end{array}$ & $\begin{array}{l}26 \\
27\end{array}$ & $\begin{array}{l}\text { IR 82616-B-B-64-3 } \\
\text { NERICA-13 }\end{array}$ & $\begin{array}{l}\text { URNVT, } 2015 \\
\text { Released }\end{array}$ & $\begin{array}{l}\text { IRRI } \\
\text { WARDA }\end{array}$ \\
\hline 10 & NERICA-4 & Released & WARDA & 28 & ARCCU16Bar-5-10-12-2-B-B & URNVT, 2015 & WARDA \\
\hline 11 & ARCCU15Bar-7-16-30-2-B-B & URNVT, 2015 & IRRI & 29 & ARCCU16Bar-12-13-14-2-B-B & URNVT, 2015 & IRRI \\
\hline 12 & WAB-450-IB-P-18-HB & URNVT, 2015 & IRRI & 30 & WAB-550-IB-P-9/1 & URNVT, 2015 & WARDA \\
\hline 13 & IR82635-B-B-47-2 & URNVT, 2015 & IRRI & 31 & ARCCU16Bar-12-12-16-3-B-B & URNVT, 2015 & WARDA \\
\hline 14 & ARCCU16 Bar-9-21-4-1-1-1 & URNVT, 2015 & IRRI & 32 & Tana & Released & IRRI \\
\hline 15 & ARCCU16 Bar-11-8-5-2-B-1, & URNVT, 2015 & IRRI & 33 & Kokit & Released & IRRI \\
\hline 16 & IR 82635-B-B-25-4 & URNVT, 2015 & WARDA & 34 & ARCCU16Bar-4-14--2-2-B-1, & URNVT, 2015 & IRRI \\
\hline 17 & IR 82635-B-B-59-2 & URNVT, 2015 & IRRI & 35 & Andassa & Released & IRRI \\
\hline 18 & ARCCU16 Bar-29-13-3-B-1 & URNVT, 2015 & IRRI & 36 & ARCCU16Bar-13-2-16-2-1-1 & URNVT, 2015 & WARDA \\
\hline
\end{tabular}

URNVT=Upland Rice National Variety Trial; IRRI=International Rice Research Institute and WARDA= West Africa Rice Development Association

Data collection: Data collection was done according to the Standard Evaluation System for Rice (SES) (IRRI, 2013). Data were collected on plant basis (average of 10 randomly taken plants) and plot basis from the central five rows $\left(4 \times 1.25 \mathrm{~m}=5 \mathrm{~m}^{2}\right)$ of each plot. Plant height $(\mathrm{PH}, \mathrm{cm})$, Panicle length $(\mathrm{PL}, \mathrm{cm})$, Culm length $(\mathrm{CL}, \mathrm{cm})$, Number of filled grains per panicle (FGPP, No.), Number of unfilled grains per panicle (UFGPP, No.), Number of fertile tillers per plant (FTTP, No.), Total number of tillers per plant (TNTPP, No.), Number of non-fertile tillers 
per plant (NFTPP, No.), Number of primary branches per panicle (NPBPP, No.), Days to 50\% heading (HD, days), Days to $85 \%$ maturity (MD, days), Biological yield (BY, q/ha), Harvest index (HI, \%), Thousand grain weight (TGW, g) and Gain yield per hectare (GY, q/ha) were considered.

\section{Statistical Analysis}

Homogeneity of error variance was tested using F-max test method of Hartley (1950), with the formula: $F-$ $\max =($ Largest MSE)/(Smallest MSE). Then after, pooled ANOVA over location was done using SAS software (SAS, 2002). Phenotypic variance for the pooled data analysis across the two location was estimated as per the formula provided by Hallauer and Miranda (1988). Phenotypic and genotypic coefficients of variation were expressed as percentage of the corresponding phenotypic and genotypic standard deviations as described by Burton (1952) and Johnson et al. (1955). Heritability in a broad sense and genetic advance for all characters was computed as the percentage of genotypic to phenotypic variance (Fehr, 1987). The correlation analysis was performed using SAS software (SAS, 2002). Path coefficient analysis developed by Wright (1921) and modified by Dewey and Lu (1959) using phenotypic and genotypic correlation coefficient were applied to determine the direct and indirect effect of yield components on grain yield.

\section{RESULTS AND DISCUSSION}

Analysis of Variance: The analysis of variance for the individual location was carried out first and significant differences $(\mathrm{P} \leq 0.05)$ among genotypes for most of the studied traits at Guraferda, however number of fertile tillers per plant, number of unfilled grains per panicle, non-fertile tillers per plant, panicle length, thousand grain weight and biological yield were found being non-significant. Similarly, the genotypes showed significant difference $(\mathrm{P} \leq 0.05)$ for plant height, number of filled grain per panicle, days to maturity, number of primary branches per panicle and grain yield however the remaining traits were showed non-significant difference among genotypes at Gojeb. Plant height, culm length, 1000-grain weight, number of primary branches per panicle, days to maturity and grain yield differed significantly among genotypes in both locations (Table 2).

Generally, the genotypes exhibited higher mean performance for some of the traits like grain yield, culm length, number of fertile tillers per plant, number of filled grains per panicle, number of primary branches per panilce, 1000-grain weight and bioloical yield at Gojeb than Guraferda experimental site. Similarly, genotypes matured relatively late at Gojeb experimental site than Guraferda. The rainfall amount recorded during the growing season of the crops at its booting stage in August was minimum at Guraferda. This might be the main reason for the lower yield performance of genotypes grown in this site than Gojeb. According to Hoshikawa (1989), water shortage at the booting stage of rice affects the meiosis stage of anthers, thereby disturbs differentiation and growth of flower primordia. This makes the panicle small, pollen becomes infertile and increases the number of empty spikelets per pancile and would end ups with lower yields. Variation of genotypes regarding panicle length between the two location might be due to the contribution of different environmental factors. According to Yoshida (1981), seasonal climatic variables adversely affect the performance of panicle length to be different even with the same genotypes grown in different locations. The significant difference among genotypes for the studied traits at each of the two sites indicates the presence of considerable variability among genotypes. 
Table 2. The mean performance, mean squares for different sources of variation and the corresponding CV in percentage for 15 traits of the individual locations

\begin{tabular}{|c|c|c|c|c|c|c|c|c|c|c|}
\hline \multirow[t]{2}{*}{ Traits } & \multicolumn{5}{|c|}{ Guraferda } & \multicolumn{5}{|l|}{ Gojeb } \\
\hline & Mean & MSG & MSE & $\mathrm{CV}$ & $\mathrm{R}^{2}$ & Mean & MSG & MSE & $\mathrm{CV}$ & $\mathrm{R}^{2}$ \\
\hline $\mathrm{PH}(\mathrm{cm})$ & 84.9 & $71.6^{*}$ & 36.1 & 7.1 & 0.8 & 80.2 & $68.3^{*}$ & 31.4 & 7.0 & 0.7 \\
\hline PL (cm) & 22 & $3.5^{\mathrm{ns}}$ & 2.2 & 6.5 & 0.7 & 23 & $2.1^{\mathrm{ns}}$ & 1.3 & 5 & 0.6 \\
\hline $\mathrm{CL}(\mathrm{cm})$ & 62.4 & $59.2 * *$ & 24.6 & 7.9 & 0.8 & 63 & $50.9^{\text {ns }}$ & 47.8 & 11 & 0.6 \\
\hline TTPP(No.) & 10.9 & $9.6^{* *}$ & 3.5 & 17.3 & 0.8 & 8.7 & $4.4^{\mathrm{ns}}$ & 3.8 & 22.3 & 0.7 \\
\hline FTPP(No.) & 6.2 & $3.3^{\mathrm{ns}}$ & 4.2 & 30 & 0.7 & 6.8 & $3.2^{\mathrm{ns}}$ & 4.2 & 30.0 & 0.6 \\
\hline NFTPP(No.) & 3.5 & $1.6^{\mathrm{ns}}$ & 1.1 & 29 & 0.8 & 1.3 & $1.4^{\mathrm{ns}}$ & 1.2 & 21.4 & 0.7 \\
\hline FGPP(No.) & 70.2 & $425.1^{*}$ & 205.1 & 20 & 0.8 & 74.8 & $491.8^{*}$ & 245.8 & 19.5 & 0.8 \\
\hline UFGPP(No.) & 18.8 & $52.1^{\mathrm{ns}}$ & 42.7 & 14 & 0.8 & 21.3 & $59.3^{\mathrm{ns}}$ & 102.7 & 14.3 & 0.6 \\
\hline TGW(g) & 23.5 & $5.7^{\mathrm{ns}}$ & 3.7 & 8.2 & 0.9 & 26.7 & $5.8^{\mathrm{ns}}$ & 6.5 & 9.5 & 0.7 \\
\hline NPBPP(No.) & 7.7 & $7.02 *$ & 3.2 & 23.2 & 0.8 & 9.2 & $8.1^{* *}$ & 2.7 & 17.9 & 0.8 \\
\hline DM(days) & 95.8 & $40.2^{* *}$ & 9.3 & 3 & 0.9 & 110.3 & $60.6^{* *}$ & 13.3 & 3.3 & 0.9 \\
\hline $\mathrm{HD}$ (days) & 55.1 & $105^{* *}$ & 43 & 11.9 & 0.9 & 65 & $68.5^{\mathrm{ns}}$ & 66.9 & 12.5 & 0.8 \\
\hline BY (q/ha) & 58.8 & $379.6^{\mathrm{ns}}$ & 226.6 & 25 & 0.7 & 66.9 & $223^{n s}$ & 337 & 27 & 0.6 \\
\hline $\mathrm{HI}(\%)$ & 0.3 & $0.008^{*}$ & 0.003 & 18.3 & 0.8 & 0.4 & $0.006^{\mathrm{ns}}$ & 0.004 & 15.8 & 0.7 \\
\hline $\mathrm{GY}(\mathrm{q} / \mathrm{ha})$ & 20.1 & $67.1 * *$ & 23.7 & 24.3 & 0.8 & 28.1 & $69.6^{*}$ & 37.3 & 21.5 & 0.8 \\
\hline
\end{tabular}

Where, ${ }^{*}, * *$ indicate significant at 0.05 and highly significant at 0.01 probability levels, respectively, ns $=$ non significant, $\mathrm{MSG}=$ mean squares of genotypes, $\mathrm{MSE}=$ mean squares of error, $\mathrm{CV}=$ coefficient of variation and $\mathrm{R}^{2}=$ coefficient of determination; $\mathrm{PH}=$ plant height, $\mathrm{PL}=$ panicle length, $\mathrm{CL}=$ culm length, $\mathrm{TTPP}=$ total number of tillers per plant, $\mathrm{FTPP}=$ number of fertile tillers per plant, $\mathrm{DH}=$ days $50 \%$ heading, $\mathrm{NFTPP}=$ number of non-fertile tillers per plant, $\mathrm{DM}=$ days to maturity, $\mathrm{FGPP}=$ number of filled grains per panicle, $\mathrm{BY}=$ biological yield, $\mathrm{TGW}=$ thousand grain weight, $\mathrm{UFGPP}=$ number of unfilled grains per panicle, $\mathrm{NPBPP}=$ number of primary branches per panicle, $\mathrm{HI}=$ harvest index and $\mathrm{GY}=$ grain yield

Prior to the combined analysis of variance, homogeneity of error variances was tested and all of the traits showed homogeneous error variances. Having this confirmation, the data were pooled across locations and combined analysis of variance were performed and presented in Table 3 . The mean squares obtained in combined analysis of variance were used to separate genotypic effects, location and their interactions.

The mean squares from the combined analysis of variance over the two locations showed statistically significant $(\mathrm{P} \leq 0.05$ or $\mathrm{P} \leq 0.01)$ difference between locations for all the traits studied, except culm length and number of unfilled grains per panicle.

The combined analysis of variance over the two locations revealed significant differences $(\mathrm{P} \leq 0.05$ or $\mathrm{P} \leq$ 0.01 ) among genotypes for most of the studied traits, except for total number of tillers per plant, number of fertile tillers per plant, number of non-fertile tillers per plant, 1000-grain weight, number of unfilled grains per panicle, days to maturity and biological yield. The presence of significant differences among the tested genotypes might be due to the existance of dissimilarity in genetic composition among them, for that fact characters may be differ in their genetic properties. Besides, environmental influences might be the possible causes of their significant differences or both. The highly significant differences observed among genotypes for some of the studied characters revealed the presence of substantial variability among genotypes. Similar results have been reported by Akinwale et al. (2011), who observed significant variation among rice genotypes for most of the characters they measured.

Genotype by location interaction effects over the two locations showed significant differences $(\mathrm{P} \leq 0.05$ or $\mathrm{P}$ $\leq 0.01$ ) for total number of tillers per plant, plant height, days to $50 \%$ heading, days to maturity and grain yield; while the rest of the traits did not show significant genotype by location interaction effects. Significant genotype by location interaction effects implied that genotypes perform differently over the two testing locations for these traits, while traits that showed non-significant genotype by location interaction effects indicates relatively consistent performance of genotypes over the two location. The consistent performance of genotypes over location help breeders by reducing the cost of varietal evaluations, hence it is expected that traits selected in one location may exhibit a similar relative performance in other locations. Also, presence of significant genotype by interactions revealed, factors present in the environment (temperature, rainfall, etc.), as well as the genetic constitution of an individual (genotype), influence the phenotypic expression of a trait. For traits with significant genotype by location interaction effects, the best genotype in one location may not be the best in the other and a separate breeding program might be required. This may indicate the importance of spatial replication of trials in order to get accurate data for rice improvement program. Similarly, significant genotype by location interaction effect were also reported for plant height and grain yield (Machunde, 2013). In line with the current result, non-significant GXL interaction was reported for number of tillers per plant, 1000-grain weight, panicle length, biological yield, 
number of fertile tillers per panicle and number of primary branches per panicle ( Konate et al., 2016).

Table 3. The mean squares for different sources of variation and the corresponding CV in percentage for the 15 traits over two locations

\begin{tabular}{lllllll}
\hline Traits & MSL(1) & MSG(35) & MSGXL(35) & MSE (60) & CV (\%) & $\mathrm{R}^{2}$ \\
\hline PH & $778.8^{* *}$ & $70.6^{* *}$ & $56.4^{*}$ & 38.3 & 7.5 & 0.7 \\
PL & $295.2^{* *}$ & $2.97^{* *}$ & $1.7^{\mathrm{ns}}$ & 1.6 & 5.1 & 0.8 \\
CL & $0.07^{\mathrm{ns}}$ & $67.9^{* *}$ & $40.7^{\mathrm{ns}}$ & 39.5 & 10.1 & 0.6 \\
TTPP & $169.8^{* *}$ & $5.6^{\mathrm{ns}}$ & $8.3^{* *}$ & 4.2 & 21.01 & 0.7 \\
FTPP & $16.08^{*}$ & $2.26^{\mathrm{ns}}$ & $4.5^{\mathrm{ns}}$ & 4.2 & 31.4 & 0.6 \\
NFTPP & $177.2^{* *}$ & $1.86^{\mathrm{ns}}$ & $1.2^{\mathrm{ns}}$ & 1.5 & 12.1 & 0.8 \\
FGPP & $903.8^{* *}$ & $858.7^{* *}$ & $57.5^{\mathrm{ns}}$ & 195.7 & 19.3 & 0.7 \\
UFGPP & $239.7^{\mathrm{ns}}$ & $53.9^{\mathrm{ns}}$ & $64.3^{\mathrm{ns}}$ & 81.7 & 14 & 0.6 \\
TGW & $354.7^{* *}$ & $6.2^{\mathrm{ns}}$ & $4.6^{\mathrm{ns}}$ & 6.0 & 9.7 & 0.8 \\
NBPP & $76.85^{* *}$ & $5.3^{*}$ & $4.5^{\mathrm{ns}}$ & 3.3 & 21.5 & 0.7 \\
DM & $7656^{* *}$ & $32^{\mathrm{ns}}$ & $150^{* *}$ & 23.7 & 4.7 & 0.9 \\
HD & $67 * *$ & $125.5^{* *}$ & $48.2^{*}$ & 26.1 & 8.4 & 0.8 \\
BY & $2349.4^{* *}$ & $373.4^{\mathrm{ns}}$ & $255.5^{\mathrm{ns}}$ & 253.0 & 25.3 & 0.7 \\
HI & $0.0469^{* *}$ & $0.010^{* *}$ & $0.0043^{\mathrm{ns}}$ & 0.0032 & 15.8 & 0.8 \\
GY & $2267.8^{* *}$ & $79.8^{*}$ & $68.3^{*}$ & 47.24 & 28.5 & 0.8 \\
\hline
\end{tabular}

Where, *,** indicate significant and highly significant at 0.05 and 0.01 probability levels, respectively. ns $=$ non significant, figures in parenthesis indicate degrees of freedom, $\mathrm{MSG}=$ mean squares of genotypes, $\mathrm{MSE}=$ mean squares of error, $\mathrm{CV}=$ coefficient of variation and $\mathrm{R}^{2}=$ coefficient of determination; $\mathrm{PH}=$ plant height, $\mathrm{PL}=$ panicle length, $\mathrm{CL}=$ culm length, $\mathrm{TTPP}=$ total number of tillers per plant, $\mathrm{FTPP}=$ number of fertile tillers per plant, $\mathrm{DH}=$ days to $50 \%$ heading, $\mathrm{NFTPP}=$ number of non-fertile tillers per plant , $\mathrm{DM}=$ days to maturity, FGPP $=$ number of filled grains per panicle, $\mathrm{BY}=$ biological yield, $\mathrm{TGW}=$ thousand grain weight, $\mathrm{UFGPP}=$ number of unfilled grains per panicle, $\mathrm{NPBPP}=$ number of primary branches per panicle, $\mathrm{HI}=$ harvest index and $\mathrm{GY}=$ grain yield

Range and Mean of Parameters: Range, mean and standard deviation of the studied characters are presented in Table 4. Filled grains differed significantly in different genotypes with a range of 24 to 123 filled grains. Maximum number of filled grains per panicle were recorded in genotype SUPERICA-1(123), ARCCU16 Bar-9-20-6-1-11(100) and ARCCU16 Bar-15-5-1-26-B-1(98), while the minimum was obtained from genotype ARCCU 16 Bar9-9-24-4-B-1(24). Genotype ARCCU16Bar-22-1-1-2-B-1 completed $50 \%$ heading after 83 days from days to seeding and was late among all other genotypes whereas genotype WAB-450-IB-P-18-HB headed earlier after 50 days of sowing. The observed significant variation among genotypes for days to heading was due to $G \times L$ interaction and due to the significant difference among the tested materials. The presence of early heading and maturing genotypes is important for climate mitigation as drought escape mechanism for areas with marginal rainfall. However, genotypes which head too early do not permit production of sufficient assimilates to fill grains and consequently might end ups with lower yield (Yoshida, 1981). For days to heading, this result is in line with the finding of Mulugeta (2015) who reported a wide range of $50 \%$ heading of 67 to 87 days.

Table 4. Estimates of mean, range and variance components for different traits in upland rice over the two locations

\begin{tabular}{llllllllll}
\hline Traits & Means \pm SD & Range & $\sigma^{2} \mathrm{~g}$ & $\sigma^{2} \mathrm{p}$ & $\begin{array}{l}\mathrm{GCV} \\
(\%)\end{array}$ & $\begin{array}{l}\mathrm{PCV} \\
(\%)\end{array}$ & $\begin{array}{l}\mathrm{h}^{2} \mathrm{~b} \\
(\%)\end{array}$ & GA & GAM $(\%)$ \\
\hline PH & $82.6 \pm 3.9$ & $75.1-94.6$ & 3.6 & 17.7 & 2.3 & 5.1 & 20.1 & 1.7 & 2.1 \\
PL & $21.5 \pm 0.8$ & $20.3-23.2$ & 0.3 & 0.7 & 2.6 & 4.0 & 42.8 & 0.8 & 3.5 \\
CL & $62.4 \pm 3.9$ & $55.8-70.3$ & 7.1 & 17.0 & 4.2 & 6.6 & 40.1 & 3.4 & 5.4 \\
NPBPP & $8.4 \pm 1.1$ & $6.3-12.8$ & 0.2 & 1.3 & 5.3 & 13.7 & 15.1 & 0.4 & 4.3 \\
FGPP & $72.5 \pm 14.6$ & $24-123$ & 200.3 & 214.7 & 19.5 & 20.2 & 93.3 & 28.2 & 38.8 \\
HD & $60.2 \pm 6.8$ & $50-83$ & 19.3 & 31.4 & 7.3 & 9.3 & 61.6 & 7.1 & 11.8 \\
HI & $0.4 \pm 0.05$ & $0.2-0.5$ & 0.0 & 0.0 & 9.4 & 12.5 & 57.0 & 0.1 & 14.7 \\
GY & $24.1 \pm 4.4$ & $15-34.3$ & 2.9 & 20.0 & 7.0 & 18.5 & 14.4 & 1.3 & 5.5 \\
\hline
\end{tabular}

Where, $\mathrm{SD}=$ standard deviation, $\sigma^{2} \mathrm{~g}=$ genotypic variance, $\sigma^{2} \mathrm{p}=$ phenotypic variance, $\mathrm{GCV}=$ genotypic coefficient of variation, $\mathrm{PCV}=$ phenotypic coefficient of variation, $\mathrm{h}^{2} \mathrm{~b}=$ broad sense heritability, $\mathrm{GA}=$ genetic advance, $\mathrm{GAM}=$ genetic advance as percentage of the mean, $\mathrm{PH}=$ plant height, $\mathrm{PL}=$ panicle length, $\mathrm{CL}=$ culm length, $\mathrm{NPBPP}=$ number of primary branches per panicle, $\mathrm{FGPP}=$ number of filled grains per panicle, $\mathrm{DH}=$ days to $50 \%$ heading, $\mathrm{HI}=$ harvest index and $\mathrm{GY}=$ grain yield.

Genotypes differed significantly in plant height which ranged from 75 to $95 \mathrm{~cm}$. The average performances of genotypes across the two locations revealed maximum and minimum plant height in genotype NERICA-4 and WAB-550-IB-P-9/1, respectively. According to IRRI (2013), upland rice height is classified as semi-dwarf $(<90$ $\mathrm{cm})$, intermediate $(90-125 \mathrm{~cm})$, and tall $(>125 \mathrm{~cm})$. Consequently, from the current study, $97.2 \%$ of the tested 
genotypes were grouped under semi- dwarf class, whereas only $2.7 \%$ fall within the intermediate category. According to Yoshida (1981), increasing yield in semi dwarf genotypes $(<90 \mathrm{~cm})$ is associated with increasing lodging resistance of rice plant. Therefore, selection of genotypes with shorter height might increase grain yield in particular areas. In agreement with the current result, Konate et al. (2016) reported a wide range of variation in plant height which ranged from 68 to $98.7 \mathrm{~cm}$ in rainfed rice. Sabouri et al. (2008) reported the importance of a wide range of variation in plant height for effective selection in rice improvement program.

Panicle length also differed in different genotypes used in the current study and it was ranged from 20 to 23 $\mathrm{cm}$. Longest and similar panicle length was observed in genotype NERICA-4, WAB415-B-11A1-2, Tana, Andassa and IR $82635-B-B-25-4$ (23 cm each), whereas the shortest panicle length was noted in genotype WAB-550-IB-P9/, IR 82635-B-B-59-2 and ARCCU16Bar-9-2-10-4-B-1 (20 cm each ). In line with the current results, significant difference among genotypes were reported with a wide range of panicle length $(21-24 \mathrm{~cm})$ by Mulegeta (2015) and (16-22 cm) by Tefera et al. (2017). Also, genotypes differed in culm length with a range of $55 \mathrm{~cm}$ to $70.3 \mathrm{~cm}$ for NERICA-4 and ARCCU 16 Bar9-26-29-1-B-1, respectively. The observed significant genotypic differences for these traits were due to the genotypic and environmental effects. In this study, harvest index differed significantly in different genotypes with a range of 20\% for ARCCU16 Bar-11-8-5-2-B-1 to 50\% for SUPERICA1, however, representative range of harvest index in upland rice was 40-60 \% (Anon, 1978; Sahu et al., 1980). According to Hay (1955), lower percentage of harvest indices $(<30 \%)$ might be reported, when rice is grown in areas of lower yield potential. Therefore, the possible reasons for lower percentage of harvest index $(20-50 \%)$ from the current study might be associated with the lower yield potential of the study areas allied with the currently changing climate. In addition, differences among genotypes, attributed from variation in tillering ability or panicle initiation and survival of spikelets might be the possible causes for the variation of genotypes for this trait. The grain harvest indices are an important trait, because it determines photosynthetic distribution between straw and grain. Consequently, it determines yield variability among the genotypes.

Number of primary branches per panicle also differed significantly among genotypes. Maximum number of primary branches per panicle was recorded in genotype NERICA-13 (13) whereas in genotypes ARCCU16Br-1212-33-3-B-1 and ARCCU16Bar-12-17-3-4-B-1 similar minimum number of primary branches per panicle (6 each) were obtained. Like other traits, grain yield also differed significantly in different genotypes which ranged from 15 to 34 quintals per hectare. Higher grain yield was obtained from SUPERICA-1 (34.3q/ha), Kokit (33.5q/ha), NERICA-4 (32.7q/ha) and NERICA-13 (29q/ha), while lower grain yield was obtained from genotype ARCCU16Bar-5-10-12-2-B-B (15 q/ha). Similarly, significant variations in grain yield were reported by Mulugeta et al. (2012) and Mulugeta (2015) who tested rice under rainfed conditions. Even though introduced genotypes gave lower yields when directly utilized in field trials as compared to the released varieties, they may also serve as donors with parents chosen from the adapted varieties because wider genetic recombination is expected in progenies of distant parents (Sneller et al., 2005).

Estimates of phenotypic and genotypic coefficient of variations: According to Sivasubramanian and Menon (1973), phenotypic coefficient of variation (PCV) and genotypic coefficient of variation (GCV) values greater than $20 \%$ are viewed as high, whereas values less than $10 \%$ are considered as low and values between 10 and $20 \%$ as moderate. Accordingly, moderate estimate of GCV was showed for number of filled grains per panicle (19.5\%). However, plant height (2.3\%), panicle length $(2.6 \%)$, culm length $(4.2 \%)$, number of primary branches per panicle $(5.3 \%)$, days to $50 \%$ heading $(7.3 \%)$, harvest index $(9.4 \%)$ and grain yield $(7 \%)$ showed low percentage of GCV. Moderate value of PCV were estimated for traits like harvest index (12.5\%), number of primary branches per panicle $(13.7 \%)$, and grain yield $(18.5 \%)$. The low percentage of PCV were obtained for plant height $(5.1 \%)$, panicle length $(4 \%)$, culm length $(6.6 \%)$ and days to $50 \%$ heading $(9.3 \%)$, while for number of filled grains per panicle $(20.2 \%)$ highest value was obtained. Generally, for all the studied traits, the results revealed a little higher phenotypic coefficient of variation than genotypic coefficient of variations.

The presence of moderate genotypic and high phenotypic coefficient of variation among some of the measured traits could be due to variance attributed to genotypic values of individuals and/or greater environmental deviation. Traits with low GCV indicates narrow genetic base and populations which were genetically more uniform (low GCV) show low heritability than genetically variable populations. Therefore, improvement on these characters should start through inducing genetic variability by hybridization or induced mutagenesis followed by selection. Because, variability is a key factor which determines the amount progress expected from selection. According to Tsion (2016), the magnitude of genetic variation is better evaluated from GCV and improvement efforts usually focused on traits with high GCV. Effective selection for filled grains per panicle will be achieved from the current genotypes on the basis of phenotypic value for yield improvement. Similar to the current report, lower percentage of genotypic and phenotypic coefficient of variations for plant height, panicle length and grain yield were reported by Konate et al. (2016). As expected, for all the characters studied phenotypic coefficient of variation is higher than the genotypic coefficient of variation. In line with this results Konate et al. (2016) reported higher values of PCV than GCV for all the studied traits in rice genotypes.

The extent of environmental influences on any traits expression can be estimated from the difference between 
the phenotypic and genotypic coefficient of variation and largest difference shows the high environmental influences, while small difference indicates high genetic influences. Consequently, from the current studies, low environmental influences and greater role of genetic factors for the expression of all traits were confirmed by the minimum difference of PCV and GCV. Similarly, Mulugeta et al. (2012) and Mishu et al. (2016) reported the higher contributions of genetic factors than environmental influences for the expression of some traits in rice plant. Estimates of broad-sense heritability and genetic advance: According to Johansen et al. (1955), the estimates of broad sense heritability were classified as low $(<30 \%)$, medium (30-60\%) and high $(>60 \%)$. Thus, high broad sense heritability estimates were obtained for number of filled grains per panicle (93.3\%) and days to $50 \%$ heading $(61.6 \%)$, while medium percentage of heritability values were found for harvest index (57\%), panicle length $(42.8 \%)$ and culm length (40.1\%). Low values of broad sense heritability were exhibited for traits like plant height (20.1\%), number of primary branches per panicle $(15.1 \%)$ and grain yield (14.4\%).

Traits with high broad sense heritability estimates might respond effectively to selection since it is expected that, environmental influences on phenotypic expression is very low. In this study, high heritability estimates for days to $50 \%$ heading and number of filled grains per panicle suggests the higher relative magnitude of genotypic variance for the total variations among the studied genotypes with respective to these traits. Therefore, based on their phenotypic expression, selection on these traits may respond effectively because it is expected that traits with high heritability estimate have a close correlation between genotypic and phenotypic appearance. Low heritability estimate was found for plant height, number of primary branches per panicle and grain yield. Consequently, improvement through selection on such traits will be difficult. Because, for traits with low broad sense heritability, phenotypic expression is not highly correlated with the genetic composition of the characters. According to Lush (1943), traits with lower value of heritability are controlled largely by non-additive gene actions and selection of phenotypically superior individual from the population will not lead to improvement. Low estimates of broad sense heritability for number of primary branches per panicle and grain yield of this study supports the previous finding by Rafii et al. (2014) and Kamara (2015). In contrary, high to medium broad sense heritability of these traits was reported by Mulugeta et al. (2012).

The estimates of genetic advance as percentage of the mean at $5 \%$ selection intensity were classified as high $(>20 \%)$, moderate $(10-20 \%)$ and low $(<10 \%)$. Thus, the estimates of genetic advance as percentage of the mean was high for number of filled grains per panicle $(38.8 \%)$ and moderate for harvest index $(14.7 \%)$ and days to $50 \%$ heading $(11.8 \%)$. However, the estimates of genetic advance as percentage of mean was low for grain yield $(5.5 \%)$, culm length (5.4\%), number of primary branches per panicle (4.3\%), panicle length $(3.5 \%)$ and plant height $(2.1 \%)$. Similar results have been reported for panicle length and number of primary branches per panicle by Demewez et al. (2014).

Heritability alone does not determine the extent of genetic progress gained after one cycle of selection, which is possible through simultaneous estimation of heritability along with genetic advance as a percentage of the mean (Ali et al., 2002). In this study, high heritability with high genetic advance as percentage of the mean for number of filled grains per panicle; high heritability with moderate genetic advance as a percentage of the mean for days to $50 \%$ heading; moderate heritability with moderate genetic advance as percentage of mean for harvest index; moderate heritability with low genetic advance as percentage of the mean for panicle length and culm length were obtained.

The expression of economically important characters through additive gene action make selection for crop improvement might be rewarding and can be confirmed by recording high value of broad sense heritability along with high genetic advance as percentage of the mean (Raia et al., 2016). Accordingly, in this study number of filled grains per panicle is less influenced by environmental factors and selection for this trait in the next generation could lead considerable improvement in rice production. Higher estimates of heritability and GAM for number of filled grains per panicle implied that, if 5\% of genotypes with greater number of filled grains per panicle are selected as parents, mean number of filled grains in the next progenies could be improved by $38.8 \%$ of 72.5 , which is 28.13 and mean value of the new population for filled grains will be increased from 72.5 to 100.6 . In line with the current result, high broad sense heritability estimate combined with high genetic advance as percentage of mean for number of filled grains per panicle was reported by Dutta et al. (2013) and Machunde (2013).

The high heritability along with moderate genetic advance as percentage of the mean for days to $50 \%$ heading, could be considered as an indication of non-additive gene acted on its expression. In this case, the high heritability of days to $50 \%$ heading exhibited might be due to favorable influence of environment rather than genotype, thereby exercising selection for this traits may not be rewarding. In agreement with this implication Sarawgi et al. (2000) reported that, the estimates of high heritability along with moderate genetic advance as percent of mean for days to flowering in rice may not be rewarding for improvement through selection. Moderate heritability jointly with low genetic advance as percent of the mean for panicle length and culm length implied, the major effect of nonadditive gene action on their expression, so that the genetic potential of such traits would be exploited through heterosis breeding followed by recurrent selection. The presence of higher environmental factors along with nonadditive gene action might be the possible causes for the lower values of heritability and genetic advance as 
percentage of the mean for grain yield, plant height and number of primary branches per panicle.

Correlation of grain yield with other characters at genotypic and phenotypic levels: The result of correlation analysis as presented in Table 5 revealed that grain yield had significant and positive genotypic association with 1000 -grain weight $\left(\mathrm{rg}=0.25^{*}\right)$, days to $50 \%$ heading $\left(\mathrm{rg}=0.51^{* *}\right)$, days to maturity $(\mathrm{rg}=0.59 * * *)$ and harvest index $\left(\mathrm{rg}=0.23^{*}\right)$. The possible reasons of such a genotypic correlation may result from pleiotropic effect or linkage of gene governing inheritance of these characters. Due to the presence of positive genetic correlation between these traits, correlated response to selection might occur, this is because selection on one trait changes allele frequency at pleiotropic loci, thus changing the phenotypes of the correlated traits. Strong positive genotypic correlation between days to maturity and grain yield, indicated that late maturing genotypes will provide higher yield due to the fact that late-maturing varieties would produce maximum tillers before initiation of the panicle and fill their grain effectively. Similarly, significant and positive genotypic correlation coefficient with grain yield were reported from earlier studies for days to 50\% heading, 1000-grain weight and days to maturity by Manchunde (2013), Mulegeta (2015) and Mishu et al. (2016) and for harvest index by Moosavi (2015).

The detected positive genotypic correlation of yield with other component traits indicated that increasing of one trait will result in increasing of the correlated trait. Therefore, priority should be given to these traits together, while making selection for rice yield improvement. Thus, from the current results, improving upland rice through selection would be effective with simultaneous consideration of grain yield with total number of tillers per plant, number of fertile tillers per plant, number of primary branches per panicle, plant height, culm length, harvest index, days to $50 \%$ heading, days to maturity and 1000-grain weight.

Significant and positive phenotypic correlation coefficients (Table 5) were estimated for grain yield with panicle length $\left(\mathrm{rp}=0.36^{* *}\right)$, number of filled grains per panicle $\left(\mathrm{rp}=0.36^{* *}\right), 1000$-grain weight $\left(0.32^{* *}\right)$, number of fertile tillers per plant $\left(\mathrm{rp}=0.32^{* *}\right)$ and number of primary branches per panicle $\left(\mathrm{rp}=0.28^{*}\right)$, while significant and negative correlation with biological yield $\left(\mathrm{rp}=-0.26^{*}\right)$. In agreement with this result, former investigators viz., Mancada et al. (2001), Dutta et al. (2002), and Karim et al. (2014), found significant and positive phenotypic association of grain yield with panicle length, fertile tillers per plant and 1000-grain weight. Abarshaher et al. (2011) also reported significant and positive phenotypic correlation of filled grains per panicle, panicle length, number of primary branches per panicle and 1000-grain weight with grain yield.

At the phenotypic level, culm length, number of unfilled grains per panicle and days to $50 \%$ heading represented positive and non-significant correlation with grain yield. However, days to maturity, number of nonfertile tillers per plant and total number of tillers per plant had negative and non-significant correlation with the resultant traits. This results implied that grain yield could not be increased by increasing total number of tillers per plant and non-fertile tillers along with using late maturing genotypes. The reduction of grain yield that might be happened in using too late maturing genotypes related with the negative correlation between grain yield and days to maturity might be due to, translocation time and fixation of photosynthates to developing grains will be short associated with a long period of vegetative phase.

Table 5. Estimation of genotypic (above diagonal) and phenotypic (below diagonal) correlation coefficients between yields, and yield component characters in 36 Upland rice genotypes

\begin{tabular}{|c|c|c|c|c|c|c|c|c|c|c|c|c|c|c|c|}
\hline Characters & $\mathrm{PH}$ & PL & $\mathrm{CL}$ & TTPP & FTPP & NFTPP & FGPP & UFGPP & TGW & NPBPP & $\mathrm{DM}$ & $\mathrm{HD}$ & BY & $\mathrm{HI}$ & GY \\
\hline $\mathrm{PH}$ & & $0.25^{*}$ & $0.649^{* *}$ & $0.461^{* *}$ & 0.016 & -0.164 & -0.039 & -0.116 & 0.163 & -0.223 & $0.309^{*}$ & $0.351^{* *}$ & 0.188 & $-0.402^{* *}$ & 0.087 \\
\hline PL & $0.56 * *$ & & 0.011 & $0.392^{* *}$ & -0.02 & $-0.249^{*}$ & -0.118 & 0.134 & $0.238^{*}$ & $-0.358^{*}$ & 0.122 & -0.089 & -0.089 & $-0.420^{* *}$ & $-0.237^{*}$ \\
\hline CL & $0.75^{* *}$ & 0.23 & & 0.091 & -0.097 & 0.031 & -0.168 & -0.149 & -0.136 & -0.045 & 0.205 & $0.379^{* *}$ & 0.152 & 0.045 & 0.146 \\
\hline TTPP & $0.39 * *$ & $0.46^{* *}$ & 0.12 & & $0.439^{* * *}$ & 0.187 & 0.075 & -0.078 & 0.145 & $-0.391^{\circ}$ & 0.061 & 0.057 & -0.065 & $-0.389^{*}$ & 0.097 \\
\hline FTPP & 0.21 & -0.05 & 0.16 & $0.36^{* *}$ & & -0.17 & 0.093 & -0.168 & 0.158 & 0.232 & -0.077 & -0.159 & 0.244 & 0.042 & 0.101 \\
\hline NFTPP & 0.16 & $0.45^{* *}$ & -0.08 & $0.57^{* *}$ & -0.14 & & -0.049 & 0.104 & $0.547^{* * *}$ & -0.099 & $-0.535^{* * *}$ & -0.227 & $-0.322^{*}$ & 0.213 & -0.165 \\
\hline FGPP & -0.05 & -0.12 & -0.04 & 0.00 & $0.25^{*}$ & -0.17 & & 0.155 & -0.096 & -0.014 & -0.015 & -0.085 & 0.012 & 0.023 & 0.212 \\
\hline UFGPP & -0.01 & -0.02 & 0.01 & -0.07 & 0.02 & -0.01 & -0.10 & & -0.16 & -0.229 & $-0.376^{* *}$ & $-0.322^{*}$ & $-0.239^{*}$ & 0.091 & -0.21 \\
\hline TGW & -0.19 & $-0.37^{* *}$ & 0.02 & $0.26^{*}$ & 0.11 & $0.50 * *$ & 0.14 & -0.07 & & 0.066 & $0.545^{* *}$ & $0.279 *$ & $0.382^{* *}$ & $-0.345^{*}$ & $0.25^{*}$ \\
\hline NPBPP & -0.14 & $-0.29^{*}$ & -0.03 & -0.15 & 0.13 & -0.16 & 0.13 & 0.12 & 0.16 & & -0.03 & -0.139 & 0.165 & $0.422^{* *}$ & 0.07 \\
\hline $\mathrm{DM}$ & $0.25^{*}$ & $0.43^{* *}$ & 0.04 & $0.32 * *$ & -0.02 & $0.32^{* *}$ & -0.09 & -0.11 & -0.21 & -0.11 & & $0.791^{* *}$ & $0.447^{* *}$ & $0.417^{* *}$ & $0.594^{* *}$ \\
\hline $\mathrm{HD}$ & $0.26^{*}$ & $0.25^{*}$ & 0.13 & 0.17 & -0.08 & 0.15 & -0.11 & -0.11 & -0.17 & -0.14 & $0.65^{* * *}$ & & $0.393^{*}$ & $-0.316^{*}$ & $0.512^{* *}$ \\
\hline BY & 0.06 & -0.15 & 0.05 & -0.09 & 0.22 & -0.21 & 0.17 & 0.00 & 0.19 & $0.29^{*}$ & 0.08 & 0.07 & & -0.07 & -0.123 \\
\hline $\mathrm{HI}$ & -0.14 & $-0.27^{*}$ & -0.03 & -0.18 & 0.07 & -0.11 & 0.02 & -0.02 & 0.02 & $0.29 *$ & $-0.27^{*}$ & -0.24 & 0.06 & & $0.236^{\circ}$ \\
\hline GY & -0.04 & $0.36^{* *}$ & 0.06 & -0.23 & $0.32^{* *}$ & -0.18 & $0.36^{* * *}$ & 0.03 & $0.32^{* *}$ & $0.28 *$ & -0.09 & 0.00 & $-0.3^{*}$ & 0.09 & \\
\hline
\end{tabular}

Where, $* * *$ Indicate significance at 0.05 and 0.01 probability levels, respectively. ns =non significant; where, $\mathrm{PH}=$ plant height, $\mathrm{PL}=$ panicle length, $\mathrm{CL}=$ culm length, $\mathrm{TTPP}=$ total number of tillers per plant, $\mathrm{FTPP}=\mathrm{fertile}$ tillers per plant, $\mathrm{DH}=$ days to $50 \%$ heading, $\mathrm{NFTPP}=$ number of non-fertile tillers per plant, $\mathrm{DM}=$ days to maturity, FGPP $=$ filled grains per panicle, $\mathrm{BY}=$ biological yield, $\mathrm{TGW}=$ thousand grain weight, $\mathrm{UFGPP}=$ unfilled grains per panicle, $\mathrm{NPBPP}=$ number of primary branches per panicle $\mathrm{HI}=$ harvest index and $\mathrm{GY}=$ grain yield

Path Coefficient Analysis: Simple correlation analysis alone does not indicate the cause and effect relationship between grain yield and its related traits. However, according to Dewey and Lu (1959) path coefficient analysis does allow partitioning of genotypic and phenotypic correlation into direct and indirect effect, thereby provides clear information on character association which helps to formulate efficient selection strategy for crop improvement. 
Phenotypic direct and indirect effects of various characters on grain yield: The path coefficient analysis revealed that, panicle length, number of primary branches per panicle, number of fertile tillers per plant, number of filled grains per panicle and thousand grain weight exerted positive and direct effect on grain yield (Table 6). The high and positive direct effect of panicle length (0.65), number of primary branches per panicle $(0.47)$, thousand grain weight $(0.52)$, number of filled grains per panicle $(0.29)$ and number of fertile tillers per plant $(0.27)$ on grain yield indicates that, keeping other independent variables constant, an increase in these traits increases grain yield. Also, increasing traits which have positive association with these traits will improve the yield of rice indirectly passing through the directly associated traits with grain yield. For instance, due to the direct and positive association, the yield of rice will be increased when panicle length $(0.65)$ is lengthy, on the other hand stimulating positively and indirectly interrelated traits like number of filled grains per panicle $(0.12)$ and number of primary branches per panicle (0.29) increases grain yield through panicle length. Therefore, considering positively and directly related traits for upland rice improvement program should be assisted by the indirectly and positively linked traits. The recorded positive and direct effect of number of fertile tillers per plant on rice grain yield is in accordance with Rao et al., (2014), Mulugeta (2015) and Priya et al. (2017). Similarly, positive and direct effect of filled grains per panicle on rice grain yield was also reported earlier by Parvathi et al. (2011) and Kishore et al. (2015). In this study, direct and negative effects of biological yield (-0.55) on grain yield were obtained. This indicates that, yield of rice might increases with the reduction of this trait, in that way most of the photosynthetic share of the crops are expected to be translocated for the grains and end ups with increased yield. Therefore, the breeder also must pay attention to the negative direct and indirect correlation that existed amongst the characters. The phenotypic path coefficient analysis residual effect $(\mathrm{R})$ was 0.33 , which implied that characters included in this analysis, explained $67 \%$ of the total variation in grain yield of rice genotypes and the remaining might be due to environmental factors ( weather, soil fertility, etc.)

Genotypic direct and indirect effects of various characters on grain yield: Genotypic path coefficient analysis for yield and yield component of rice revealed, higher and positive direct effects of days to heading (0.7), thousand grain weight $(0.62)$, days to maturity $(0.32)$ and harvest index $(0.23)$ on rice grain yield (Table 7$)$. High direct effect of these traits, therefore, give the impression to be the main factor for their strong relationship with grain yield and should be considered as important traits for rice improvement via direct selection. In line with the current results, for days to heading and harvest index, postive and direct effect on rice grain yield were reported by Badri et al. (2016). Similarly, for thousand grain weight, this result was in parallel with Bagheri et al. (2011) who reported that thousand grain weight $(0.56)$ in rice had the highest and positive direct effect on rice grain yield. The indirect effect of days to maturity and days heading on grain yield via thousand grain weight were positive. Traits like thousand grain weight, days to $50 \%$ heading and harvest index showed positive and indirect association with grain yield passing through days to maturity. The least but positive and direct effect of harvest index $(0.23)$ on grain yield could be compensated via the high and positive indirect effect of days to maturity (0.5). Accordingly, the yield of rice could be increased with increasing the percentage of harvest index along with using late maturing genotypes. Thus, considering harvest index alone as most important direct yield components of rice might be ineffective in rice improvement program. Similarly, Moosavi (2016) reported positive and direct effects of harvest index on rice grain yield and positive indirect effects of days to maturity through harvest index.

Therefore, from the present genotypic path coefficient analysis, we observed that, rice yield components like thousand grain weight, days to maturity, days to $50 \%$ heading and harvest index had positive direct effect on yield, which indicates considering of these traits during selection of rice genotypes would be more rewarding to evolve potential varieties of rice for rainfed ecology. A higher magnitude and positive direct effects of thousand grain weight on rice grain yield was observed from genotypic path coefficient than phenotypic path coefficient analysis, which indicates the high masking effect of the environment on the expression of this trait.

Table 6. Phenotypic direct and indirect effects of six component characters on grain yield in upland rice

\begin{tabular}{lllllllll}
\hline Characters & Phenotypic direct effect & PL & FTPP & FGPP & TGW & NPBPP & BY & rp \\
\hline PL & $\mathbf{0 . 6 5}$ & & -0.05 & 0.12 & -0.5 & 0.29 & -0.15 & $\mathbf{0 . 3 6}^{* *}$ \\
FTPP & $\mathbf{0 . 2 7}$ & 0.05 & & 0.25 & 0.03 & 0.13 & -0.4 & $\mathbf{0 . 3 2}^{\text {** }}$ \\
FGPP & $\mathbf{0 . 2 9}$ & -0.19 & 0.23 & & 0.12 & 0.09 & -0.17 & $\mathbf{0 . 3 6}^{* *}$ \\
TGW & $\mathbf{0 . 5 2}$ & 0.19 & 0.11 & 0.14 & & 0.16 & -0.8 & $\mathbf{0 . 3 2}^{* *}$ \\
NPBPP & $\mathbf{0 . 4 7}$ & -0.49 & 0.04 & 0.13 & 0.09 & & 0.01 & $\mathbf{0 . 2 8}^{*}$ \\
BY & $\mathbf{- 0 . 5 5}$ & -0.15 & 0.22 & 0.12 & -0.2 & 0.3 & & $\mathbf{- 0 . 3}^{*}$ \\
\hline
\end{tabular}

Residual effect $=\sqrt{0.11}=0.33$

Where, $\mathrm{PL}=$ panicle length, $\mathrm{FTPP}=$ number of fertile tillers per plant, FGPP =number of filled grains per panicle, $\mathrm{BY}=$ biological yield, $\mathrm{TGW}=$ thousand grain weight, $\mathrm{NPBPP}=$ number of primary branches per panicle and $\mathrm{GY}=$ grain yield 
Table 7. Genotypic direct and indirect effects of four component characters on grain yield in upland rice

\begin{tabular}{lllllll}
\hline Characters & \multicolumn{1}{c}{ Genotypic direct effect } & TGW & DM & HD & HI & rg \\
\hline TGW & $\mathbf{0 . 6 2}$ & & 0.31 & 0.03 & -0.71 & $\mathbf{0 . 2 5}^{*}$ \\
DM & $\mathbf{0 . 3 2}$ & 0.23 & & 0.04 & 0.01 & $\mathbf{0 . 5 9}^{* *}$ \\
HD & $\mathbf{0 . 7}$ & 0.08 & 0.55 & & -0.8 & $\mathbf{0 . 5 1}^{* *}$ \\
HI & $\mathbf{0 . 2 3}$ & -0.22 & 0.5 & -0.28 & & $\mathbf{0 . 2 4}^{*}$ \\
\hline
\end{tabular}

Residual effect $=\sqrt{0.09}=0.30$

Where, $\mathrm{DH}=$ days to $50 \%$ heading, $\mathrm{DM}=$ days to maturity, $\mathrm{TGW}=$ thousand grain weight, $\mathrm{HI}=$ harvest index and $\mathrm{GY}=$ grain yield.

\section{CONCLUSION}

The results from pooled analysis of variance showed that there is a marked amount of genetic variability among genotypes. This indicates that the genotypes are not closely related and could serve as a genetic source for multiple attributes. In this study, high heritability estimates for days to $50 \%$ heading and number of filled grains per panicle suggests the higher relative magnitude of genotypic variance for the total variations among the studied genotypes with respective to these traits. Therefore, based on their phenotypic expression, selection on these traits may respond effectively because it is expected that traits with high heritability estimate have a close correlation between genotypic and phenotypic appearance. Low environmental influences and greater role of genetic factors for the expression of rice traits were confirmed by the minimum difference of PCV and GCV. The detected positive and significant correlation indicated that, increases in the value of one trait results in increasing the correlated traits. Hence, traits like panicle length, fertile tillers per plant, filled grains per panicle, thousand grain weight, number of primary branchs per panicle, harvest indix and days to maturity were obtained to be an important component of rice grain yield.

\section{REFERENCE}

Akinwale, M.G., Gregorio, G., Nwilene, F., Akinyele, B.O., Ogunbayo, S.A. and Odiyi, A.C., 2011. Heritability and correlation coefficient analysis for yield and its components in rice (Oryza sativa L.). African Journal of Plant Science, 5(3), pp.207-212.

Alemu, D. and Assefa, G., 2016. Evaluation of Improved Upland Rice Varieties for Potential Rice Producing Area Kemashi Zone of Benishangul Gumze of Ethiopia, Ecology and Evolutionary Biology. Vol. 1, No. 1, pp. 16. doi: 10.11648/j.eeb.20160101.11

Ali, Z., Khan, A.S. and Asad, M.A., 2002. Salt tolerance in bread wheat: Genetic variation and heritability for growth and ion relation. Asian J. Plant Sci, 1, pp.420-422.

Badri, A., Rassam, G., Dadkhah, A.,and Mohaddesi, A., 2016. Path Coefficient Analysis for the yield-related traits of rice lines in north Iran. Annales of theWest University of Timisoara. Series of Biology, 19(2), p.119.

Bagati, S., Singh, A., Salgotra, R., Bhardwaj, R., Sharma, M., Rai, S. and Bhat, A., 2016. Genetic variability, heritability and correlation coefficients of yield and its component traits in basmati rice (OryzaSativa 1.). Sabraojournals of breeding \& genetics, 48(4).

Basavaraja, T., Asif, M., Mallikarjun, S.K. and Gangaprasad, S., 2013. Variability, heritability and genetic advance for yield and yield attributing characters in different local rice (Oryza sativa L.) cultivars. Asian Journal of Bio Science, 8(1), pp.60-62.

Burton, G.W., 1952. Quantitative inheritance in grasses. Proceedings of the 6th Grassland Congress 1: 277-285.

CSA (Central Statistical Authority), 2000. The federal Democratic Republic of Ethiopia. Statistical Abstracts. Addis Ababa: CSA.

CSA, 2015. Agricultural Sample Survey Series, 2014/2015: Report on Area and Production of Major Crops (Private Holdings, Main Season). Statistical Bulletin No. 578. Central Statistics Authority of Ethiopia, Addis Ababa, Ethiopia. pp. 14-16.

CSA, 2016. Agricultural Sample Survey Series, 2015/2016: Report on Area and Production of Major Crops (Private Holdings, Main Season). Statistical Bulletin No. 584. Central Statistics Authority of Ethiopia, Addis Ababa, Ethiopia. pp. 14-16.

Demewez, F., Getachew, A., Siddalingaiah, M. and Tilahun, T., 2014. Genetic Variability, Heritability and Correlation Coefficient Analysis for Yield and Yield Component Traits in Upland Rice (Oryza sativa L.). East African Journal of Science, 8(2), pp.147-154.

Dewey, D.R., and Lu, K., 1959. A correlation and pathcoefficient analysis of components of crested wheatgrass seed production. Agronomy Journal, 51(9), pp.515-518.

Dutta, P. and Borua, P.K., 2013. Morphological traits as selection indices in rice: A statistical view. Universal Journal of Agricultural Research, 1(3), pp.85-96.

FAOSTAT, 2016. Agriculture Organization of the United Nations Statistics Division Production Available in http://faostat3. fao. org/browse/Q/QC/S [Review date: April 2015].

Fehr, W.R., 1987. Principles of Cultivar Development: Theory and Technique. Vol.1,Mc Graw Hill, New York. 
Hadush, H., 2015. Factors Affecting Adoption of Upland Rice and Its Implication on System Innovation: The Case of Tselemti District, North Western Zone of Tigray, Ethiopia (MSc thesis, Haramaya University).

Hallauer, A.R. and Miranda, J.B., 1988. Quantitative Genetics in Maize Breeding, 2nd edn, Iowa St. Univ. Press, Ames, IA.

Hartley, H.O., 1950. The maximum F-ratio as a short-cut test for heterogeneity of variance. Biometrika, 37(3/4), pp.308-312.

Hay, R.K.M., 1995. Harvest index: a review of its use in plant breeding and crop physiology. Annals of applied biology, 126(1), pp.197-216.

Heluf, G. and Mulugeta, S., 2006. Effects of mineral N and P fertilizers on yield and yield components of flooded lowland rice on vertisols of Fogera Plain, Ethiopia. Journal of Agriculture and Rural Development in the Tropics and Subtropics (JARTS), 107(2), pp.161-176.

Jeon, J.S., Jung, K.H., Kim, H.B., Suh, J.P. and Khush, G.S., 2011. Genetic and molecular insights into the enhancement of rice yield potential. Journal of Plant Biology, 54(1), pp.1-9.

Johnson, H.W., Robinson, H.F. and Comstock RE., 1955. Estimation of genetic and environmental variability in soybeans. Agron. J. 47:314-318.

Konate, A.K., Zongo, A., Kam, H., Sanni, A. and Audebert, A., 2016. Genetic variability and correlation analysis of rice (Oryza sativa L.) inbred lines based on agro-morphological traits. African Journal of Agricultural Research, 11(35), pp.3340-3346.

Kumar, V., Koshta, N., Sohgaura, N. and Koutu, G.K., 2014. Genetic Evaluation of RILs Population for Yield and Quality Attributing Traits in Rice (Oryza sativa L.). J. Agric. Technol, 1(1), pp.43-51.

Machunde, Z.A., 2013. Variation and inter relationships among yield and yield components in lowland rice genotypes (Oryza sativa L.) in Mwanza Region (Doctoral dissertation, Sokoine University of Agriculture).

Mishu, M.F.K., Rahman, M.W., Azad, M.A.K., Biswas, B.K., Talukder, M.A.I., Kayess, M.O., Islam, M.R. and Alam, M.R.,2016 Study on Genetic Variability and Character Association of Aromatic Rice (Oryza sativa L.) Cultivars.

Moosavi, M., Ranjbar, G., Zarrini, H.N. and Gilani, A., 2015, January. Correlation between morphological and physiological traits and path analysis of grain yield in rice genotypes under Khuzestan conditions. In Biological Forum (Vol. 7, No. 1, p. 43).

Moosavi, M., Ranjbar, G., Zarrini, H.N. and Gilani, A., 2015, January. Correlation between morphological and physiological traits and path analysis of grain yield in rice genotypes under Khuzestan conditions. In Biological Forum (Vol. 7, No. 1, p. 43).

Mulugeta, B.J., 2015. Genetic Variability and Association among Yield and Yield Related Traits in Selected Upland Rice (Oryza sativa L. and Oryza glaberrima Steud) Genotypes (Thesis, Haramaya University).

Mulugeta, S., Sentayehu, A. and Kassahun, B., 2012. Genetic variability, heritability, correlation coefficient and path analysis for yield and yield-related traits in upland rice (Oryza sativa L.). Journal of plant sciences, 7 (1), p.13.

Osekita, O.S., Akinyele, B.O. and Odiyi, A.C.,2014. Evaluation of Exotic Rice Varieties for Genetic Parameters in a Nigerian Agro-Ecology.

Priya, C.S., Suneetha, Y., Babu, D.R. and Rao, V.S., 2017. Inter-relationship and path analysis for yield and quality characters in rice (Oryza sativa L.).

Raia, P.K., Sarkera, U.K., Islamb, A.S., Rahmana, M.A. and Hasan, M.,2016. Genetic study and selection in theF4 generation of rice (Oryza sativa L.). Journal of Bioscience and Agriculture Research, 9(01), pp.768-774.

Rao, V.T., Mohan, Y.C., Bhadru, D., Bharathi, D. and Venkanna, V., 2014. Genetic Variability and Association Analysis in Rice.

Sabouri, H., Rabiei, B. and Fazalalipour, M. 2008. Use of selection indices based on multivariate analysis for improving grain yield in rice. Rice Science. 15 (4): 303-310.

SAS Institute, 2002. SAS/STAT Guide for Personal Computers, Version 9.2 editions.

Sneller, C.H., Nelson, R.L., Carter Jr., T.E. and Cui, Z,. 2005. Geneticdiversity in crop improvement: The soybean experience. In: Genetic and Production Innovations in Field Crop Technology: New Developments in Theory and Practice, pp. 103-144, (Kang, M.S., ed). International Book Distributing Co., Delhi, India.

Tefera, A., Sentayehu, A. and Leta, T., 2017. Genetic Variability, Heritability and Genetic Advance for Yield and its Related Traits in Rainfed Lowland Rice (Oryza sativa L.) Genotypes at Fogera and Pawe, Ethiopia. Adv Crop Sci Tech 5: 272. doi: 10.4172/2329-8863.1000272

Tsion, F., 2016. Genetic Diversity of Ethiopian Tef (Eragrostis Tef (Zucc.) Trotter) Varieties as Revealed by Morphological and Microsatellite Markers (MSc. thesis, Addis Ababa University).

US Department of Agriculture (USDA), 2016. USDA programs related crop production data. USDA Program Aid. Agricultural Research Service, Washington, DC.

Yoshida, S.,1981. Fundamentals of rice crop science.1st Edn., International Rice Research Institute, Philippines, ISBN:971-104-052-2, pp:267. 